\title{
High adherence level to artemisinin-based combination therapies in rural settlement II years after their introduction in the health system, Nanoro, Burkina Faso
}

This article was published in the following Dove Medical Press journal:

Patient Preference and Adherence

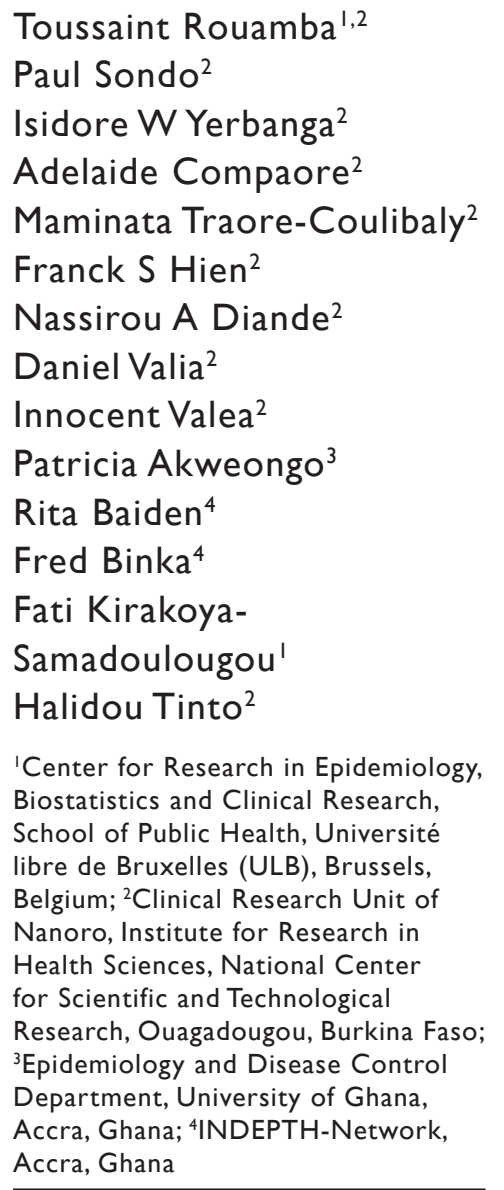

Correspondence: Toussaint Rouamba Clinical Research Unit of Nanoro, Institute for Research in Health Sciences, National Center for Scientific and Technological Research, 528, Avenue Kumda-Yoore, BP 218 Ouagadougou CMS II, Ouagadougou, Burkina Faso Tel +22666653204

Email rouambatoussaint@gmail.com
Purpose: In 2005, Burkina Faso changed its first-line treatment for uncomplicated malaria from chloroquine to artemisinin-based combination therapies (ACTs). Patient adherence to ACTs regimen is a keystone to achieve the expected therapeutic outcome and prevent the emergence and spread of parasite resistance. Eleven years after the introduction of ACTs in the health system, this study aimed to measure adherence level of patients in rural settlement and investigate the determinants of nonadherence.

Patients and methods: The study was carried out at public peripheral health facilities from May 2017 to August 2017 in Nanoro health district, Burkina Faso. An electronic semistructured questionnaire was used for data collection from patients with an ACT prescription at their medical consultation exit visit and during home visit at day $5 \pm 2$. Adherence level was measured through self-report and pill counts. Logistic regression was performed to identify factors for nonadherence.

Results: The analysis was conducted on 199 outpatients who received ACT as prescription. About $92.5 \%$ of ACT prescriptions included artemether-lumefantrine tablets. Adherence level was measured in $97.0 \%$ of included patients at day $5 \pm 2$. Of these, $86.0 \%$ were classified as "complete adherent" and $14.0 \%$ as "nonadherent". In univariate analysis, patients/caregivers who considered that affordability of ACTs was easy seemed to be less adherent to the treatment regimen (OR: 0.26; 95\% CI: 0.07-0.70). In univariate and multivariable analyses, patients/ caregivers who did not receive advices from health care workers (HCWs) were more likely to be nonadherent to the prescribed ACTs (adjusted OR: 3.21; 95\% CI: 1.13-9.12).

Conclusion: This study demonstrates that majority of those who get an ACT prescription comply with the recommended regimen. This emphasizes that in rural settings where ACTs are provided free of charge or at a subsidized price, patient adherence to ACTs is high, thus minimizing the risk of subtherapeutic concentrations of the drug in blood which is known to increase resistance and susceptibility to new infections. Therefore, to address the problem of patient nonadherence, strategy to strengthen communication between HCWs and patients should be given greater consideration.

Keywords: malaria, hyperendemic area, drug prescription, artemether-lumefantrine, amodiaquine-artesunate

\section{Introduction}

Despite a substantial increase of international funding in malaria control activities, combined with the large availability of new antimalarial drugs for management of 
malaria cases, ${ }^{1}$ the disease still remains the major cause of morbidity and mortality, especially in sub-Saharan Africa (SSA) countries. ${ }^{2}$ As recommended by WHO in the "Test-Treat-Track" initiative, an early and accurate diagnosis of malaria cases followed by the initiation of prompt treatment using artemisinin-based combination therapies (ACTs) significantly reduces the mortality rates related to malaria. ${ }^{3-6}$

In Burkina Faso, until 2005, the management of uncomplicated malaria was based on chloroquine as first-line treatment. To overcome the challenges of treatment failures due to chloroquine resistance, ${ }^{7,8}$ National Malaria Control Program introduced the ACTs (artemether-lumefantrine [AL] and artesunate-amodiaquine [ASAQ] $)$ in its guidelines for the treatment of uncomplicated malaria 11 years ago. ${ }^{9}$ However, there was a limited access to health services at the national level. Indeed, access to health care is disparate and difficulties with regard to treatment affordability and distance to health services represent the main barriers. Curative care access among children suffering from common infectious diseases (malaria, diarrhea, and pneumonia) was estimated to be around $50 \%-69.5 \% .^{10,11}$

To ensure affordability to these new effective and safe antimalarial drugs, the government adopted a policy which provided ACTs free of charge to children under 5 years and to pregnant women (after the first trimester of pregnancy) attending public health facilities, ${ }^{12}$ and subsidized ACTs for the rest of the population. ${ }^{13}$ However, despite these new recommendations and government efforts, national health statistics reported in 2017 that the burden of malaria, especially among children under 5 years, remains high. Nearly $43.5 \%$ of all outpatient attendance in peripheral health facilities were due to malaria. ${ }^{14}$ Additionally, severe malaria accounted for almost $55 \%$ of all pediatric inpatient admissions in hospitals and led to $\sim 4,144$ deaths. ${ }^{14,15}$ The prevalence of high morbidity and mortality rates could be explained partly by the "low-effectiveness" of malaria control policies in the actual conditions of the health system. While sufficient knowledge exists with regard to malarial symptoms and treatment options, barriers to prevention and care-seeking through the use of rapid diagnosis tests (RDTs) remain relatively low. ${ }^{16}$

In SSA countries in general, and especially in Burkina Faso, the management of uncomplicated malaria using ACTs is not followed by regular monitoring adapted to the local context in order to assess its effectiveness components, especially adherence of patients. However, previous studies reported poor adherence to the recommended treatment regimens, causing subtherapeutic concentrations of the drug in blood, which is one of the main factors underlying parasite resistance and recurrent malarial infections. ${ }^{17-20}$
Several observational studies (cross-sectional and prospective) carried out across SSA to assess patient adherence level to ACTs (mainly pill counts and self-report) revealed that the mean proportion of adherence to ACTs varied substantially and ranged between $32.2 \%$ and $96.0 \%{ }^{21-26}$ Recently, the emergence of resistance to artemisinin compounds has been proven in South-East Asia ${ }^{27,28}$ and seems to be suspected in Central Africa (Equatorial Guinea), ${ }^{29}$ and there is a growing concern that this may spread to other endemic areas. Given that nonadherence to ACTs is the main source of emergence and spread of parasite resistance, caution should be taken to guarantee a good practice regarding provider compliance and patient/caregiver adherence to treatment guidelines.

In Burkina Faso, to our knowledge, there is no published data about adherence level of patients to ACTs in public health facilities. ${ }^{30}$ In this context, we aimed to contribute to address this gap by evaluating adherence level of patients to ACTs and factors associated with nonadherence in patients attending public health facilities in rural setting of Burkina Faso. On the other hand, this study, by providing data on patient adherence level to ACTs 11 years after their introduction into the health system, will contribute to the implementation of new measures or strengthen existing measures in order to prevent the development of resistance to artemisinin in the plasmodial strains.

\section{Patients and methods Study setting}

This study was carried out in the Nanoro Health and Demographic Surveillance System (HDSS) catchment area. ${ }^{31}$ Nanoro district is one of the seven health districts of the Central-West health region of Burkina Faso. The HDSS area $\left(594.3 \mathrm{~km}^{2}\right)$ lies between longitudes $1^{\circ} 892537$ and $2^{\circ} 83146$ West and latitudes $12^{\circ} 857955$ and $12^{\circ} 872863$ North and includes a total of 24 villages and seven peripheral health facilities. In this rural area, malaria is markedly seasonal with high transmission observed during the rainy season (July to December). In 2009, the number of HDSS inhabitants was estimated at about 60,000 , of whom $20 \%$ were children less than 5 years of age. ${ }^{31}$

Malaria was one of the common diseases in this area, accounting for about $43.5 \%$ of all outpatient consultations and $60.5 \%$ of hospitalizations. ACTs (AL and ASAQ) are prescribed free of charge to children less than 5 years of age since 2016 and represent the first-line treatment for uncomplicated malaria. According to national health statistics, 104,887 cases of uncomplicated malaria treated with ACTs were reported in 2017 in Nanoro health facilities. ${ }^{14}$ For our study, three peripheral health facilities (Nanoro, Nazoanga, 
and Seguedin) of the Nanoro HDSS were selected to assess the adherence level to ACTs (Figure 1).

\section{Study design and study participants}

This was an observational, follow-up study that was carried out among patients who were treated with the first-line antimalarial drugs between May and August 2017. All patients attending the selected health facilities in the HDSS catchment area and for whom a first-line treatment with an ACT was prescribed for uncomplicated malaria by health care workers (HCWs) were invited to participate. Those who had signed informed consent (a parent/guardian
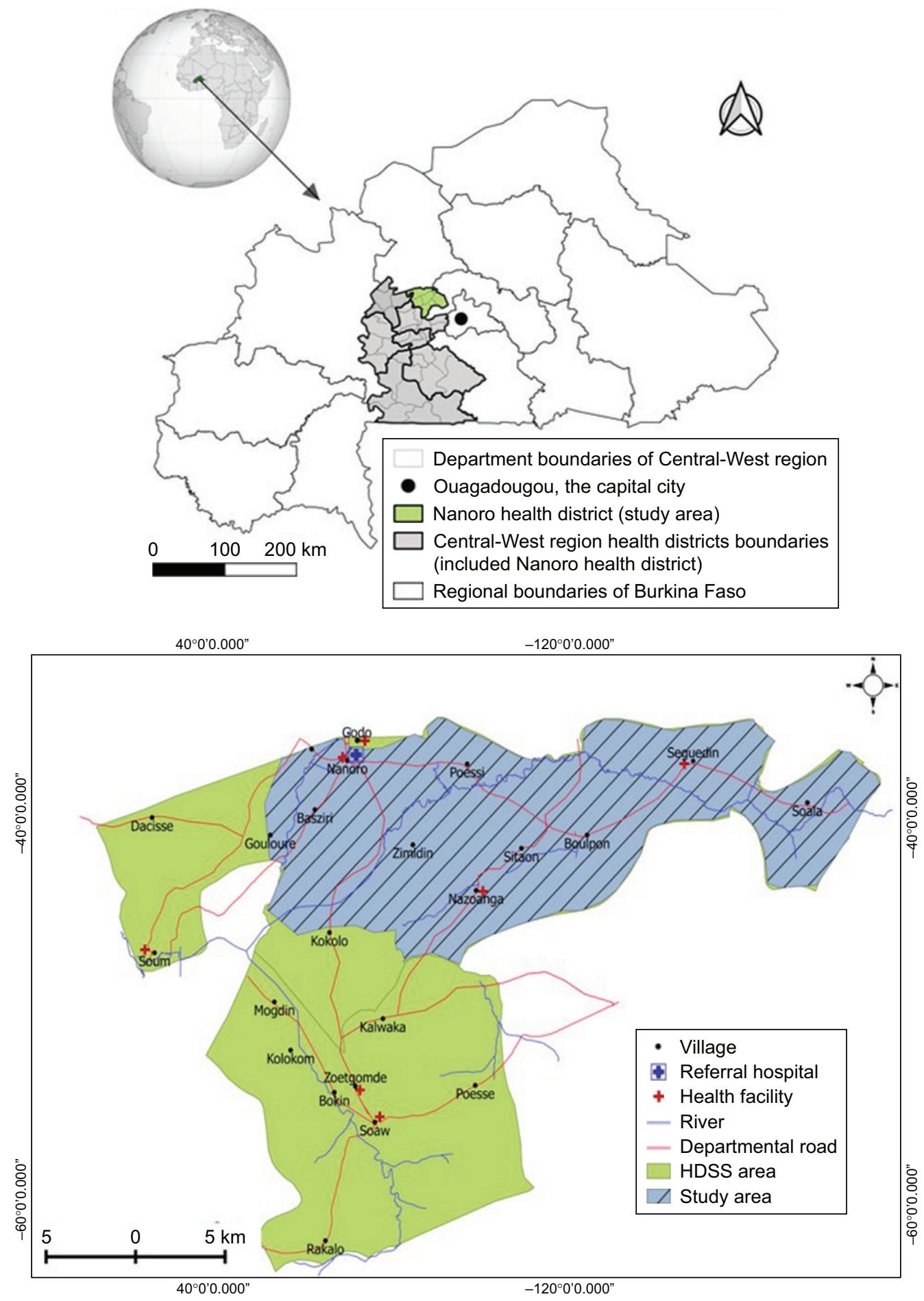

Figure I Map showing Burkina Faso location with regional area boundaries (top) and map of Nanoro Health and Demographic Surveillance System and the study area (bottom). Abbreviation: HDSS, Health and Demographic Surveillance System. 
for children below 18 years of age) were included in the study. HCWs represent a group of people whose primary intent is to enhance health. ${ }^{32}$ In this study, HCWs were nurses (public agents of government of Burkina Faso), whose main objective was to provide primary health care (curative and preventive) to the community or local population.

After patients/caregivers attended a health facility, an exit interview was performed at day 0 and day $5 \pm 2$ after day 0 (between 3 and 7 days after day 0 , ie, drug prescription day) at home.

\section{Sample size}

Sample size was estimated according to the following formula: $\mathrm{n}=Z_{\alpha / 2}{ }^{2} * p^{*}(1-p) / i^{2}$, where $Z_{\alpha / 2}$ is the critical value of the normal distribution at $\alpha=5 \% ; i=6 \%$, represents the absolute precision or the margin of error; and $p=90 \%$, represents the estimated average level of adherence.

A design effect of 1.5 was added to account for the clustering in health facilities. For the last day (day 5 \pm 2 ) evaluation, $15 \%$ losses were added for the follow-up. The sample was further increased by $10 \%$ to account for contingencies. A total of 199 subjects from three health facilities targeted for the study were enrolled in the study. A sampling with probability proportional to the population size of each community was performed.

\section{Recruitment and data collection method}

Study participants were recruited and interviewed at health facilities after their medical consultation at the exit of the health service (day 0). During this interview, sociodemographic data (age, sex, and village), drug prescription information (drug name, number of tablets, dose, and duration), and concomitant medications were recorded. Information regarding actions taken by HCWs during medical consultation (malaria confirmation by RDT, supervision of the administration of first dose of prescribed ACT, request for time when the patient last consumed food, and advices given to patient, especially in case of occurrence of vomiting or recurrent high fever) was recorded.

Patients were contacted on day $5 \pm 2$ at home by trained field workers, in order to capture data about adherence and recovery status. In case of persistence of fever or any health issues after the last visit, patients were encouraged to attend the health center for medical care. During this home visit, field workers recorded mainly the information regarding:

- Date of the visit/contact

- Clinical condition (recovered status or continuation of the illnesses)

- Number of tablets of ACT remaining
In cases of leftover tablets, the reason for not complying with the treatment regimen was requested. In that case, the leftover tablets and/or packages were photographed using the tablet (device) camera, in order to allow and facilitate the verification by supervisors.

\section{Expected output}

The main output estimated was the proportion of patients treated with an ACT who completed the recommended age-specific course of treatment. Currently, it is noticeable that no gold standard has been clearly established to assess patient adherence level to medications. ${ }^{33,34}$ For our study, adherence level was measured retrospectively on the basis of two parameters: history (self-report through interviews) and examination of remaining doses (pill counts):

- Complete adherence was defined as any case where the patient or caretaker stated that they had taken all of the tablets as recommended and the physical count of the pills confirmed the expected number of pills.

- Nonadherence was defined as any case where the patient stated that they did not take all of the tablets as recommended by the time of follow-up visit and/or a physical count of the pills demonstrated greater than or less than the expected number of pills.

\section{Data management and statistical analyses}

Data were collected in electronic form using an open-source software Open Data Kit (ODK) Collect setup. ${ }^{35}$ ODK is an open-source suite of tools that include ODK Collect, an android-based mobile client that acts as the interface between the user and the underlying form used to collect data. ${ }^{36}$ Data were captured face to face at the exit of medical consultation by nurses and at home by field workers using a semi-structured questionnaire. Once the data had been collected, they were checked for completeness and consistency by physicians before uploading them into the server (ODK aggregate). Then the data were downloaded from the server to control for coherence effects by using the study data manager. In case of inconsistent data, data clarification forms were generated to sort them out.

All analyses were performed using $\mathrm{R}$ software version 3.4.2 (R Development Core Team, R Foundation for Statistical Computing, Vienna, Austria). Descriptive analysis was performed to estimate the proportion of adherence level. Univariate and multivariable logistic regression analyses were performed to determine factors associated with nonadherence to ACTs. Multivariable analysis was built using backward stepwise regression models, with Akaike information 
criterion (AIC) as criterion for best model selection; model exhibiting a low value of AIC indicates best model. Crude and adjusted ORs derived from the logistic regressions were presented with $95 \% \mathrm{CI}$. A $P$-value $<0.05$ was considered as statistically significant.

\section{Ethics approval}

This study is part (baseline assessment) of a large community program conducted to determine the effectiveness of pyramax in Nanoro health district. Ethical approvals were obtained from institutional ethics committees at "Institut de Recherche en Sciences de la Santé", Bobo Dioulasso, Burkina Faso (deliberation n ${ }^{\circ}$ 20-2017/CEIRES)", and the National Health Ethics Committee of Burkina Faso (2017-6-075/ CERS). The study purpose and procedures were explained to the potential participants by the study staff in the local languages. Participants who fulfilled the inclusion criteria and agreed to participate in the survey were asked to provide a written inform consent. A parent or legal guardian provided written informed consent on behalf of any patient under 18 years of age. All procedures followed were carried out in accordance with the Helsinki Declaration as revised in 2013.

\section{Results}

\section{Population baseline characteristics}

From May 2017 to August 2017, 199 patients were included in the study and 97\% (193/199) were successfully visited at day $5 \pm 2$ for scheduled home visit. Table 1 summarizes

Table I General characteristics of the population

\begin{tabular}{|c|c|c|}
\hline Variables & Frequency & $\%$ \\
\hline Number of participants interviewed at exit visit & 231 & 96.7 \\
\hline Participants with exploitable data & 199 & 86.1 \\
\hline \multicolumn{3}{|l|}{ Gender } \\
\hline Female & 107 & 53.8 \\
\hline Male & 92 & 46.2 \\
\hline \multicolumn{3}{|l|}{ Age group } \\
\hline Under 5 years & 149 & 74.9 \\
\hline 5 years and above & 50 & 25.1 \\
\hline \multicolumn{3}{|l|}{ Blood smear performed by $\mathrm{HCW}$} \\
\hline Yes & 166 & 83.4 \\
\hline No & 33 & 16.6 \\
\hline \multicolumn{3}{|l|}{ Type of ACT prescribed } \\
\hline Artemether-lumefantrine & 184 & 92.5 \\
\hline Artesunate-amodiaquine & 15 & 7.5 \\
\hline \multicolumn{3}{|l|}{ Patient knows ACT name } \\
\hline Yes & 80 & 40.2 \\
\hline No & 119 & 59.8 \\
\hline
\end{tabular}

Abbreviations: ACT, artemisinin-based combination therapy; $\mathrm{HCW}$, health care worker. the general characteristics of study population. The median age of the participant was 2.6 (IQR: 1.4-5.0) years and the maximum age was 68.5 years. About three-quarters $(74.9 \%)$ of patients were less than 5 years of age. Nearly $53.8 \%(107 / 199)$ of patients were female and approximately one-sixth of the patients reported not having a blood smear collection for malaria diagnosis confirmation by HCW. Approximately, 59.8\% (119/199) of patients/caregivers who received antimalarial drugs at the health facilities did not know the names of the ACTs prescribed.

\section{ACT prescription practices}

The prescription practice of ACTs by HCW is summarized in Table 2. More than half $(59.8 \%)$ of the study participants reported that they had not received any advice from the $\mathrm{HCW}$, particularly in case of vomiting due to the ACTs prescribed. It was noticed that more than one-third $(\sim 37.7 \%)$ of participants did not take the first dose of their treatment at the health facility level (directly observed treatment strategy). Among those who took their ACTs at health facility, $62.1 \%(77 / 124)$ initiated their medication administration with meal.

Table 2 Artemisinin-based combination therapy prescription practice

\begin{tabular}{|l|l|l|}
\hline Variables & Frequency & $\%$ \\
\hline HCW had given advice to the patient & 40.2 \\
\hline Yes & 80 & 59.8 \\
\hline No & 119 & 62.3 \\
\hline First dose of ACT taken under supervision at HF \\
\hline Yes & 124 & 37.7 \\
\hline No & 75 & \\
\hline Day 0 drug taken with meal & \\
\hline Yes & 77 & 62.1 \\
\hline No & 47 & 37.9 \\
\hline Day 0 drug taken with milk & \multicolumn{2}{l|}{} \\
\hline Yes & 17 & 22.1 \\
\hline No & 60 & 77.9 \\
\hline Vomiting with first dose of ACT & \\
\hline Yes & 7 & 5.6 \\
\hline Day 0 drug re-dosed after vomiting & 71.4 \\
\hline Yes & 5 & 28.6 \\
\hline No & 2 & \\
\hline
\end{tabular}

Notes: a Denominator included only patients who took ACT under supervision at health facility. 'Denominator included only patients who took ACT with meal under supervision at health facility. 'Denominator included only patients who took ACT under supervision at health facility and experienced vomiting.

Abbreviations: ACT, artemisinin-based combination therapy; $\mathrm{HCW}$, health care worker; HF, health facility. 
Table 3 Artemisinin-based combination therapy adherence in Nanoro health district

\begin{tabular}{|c|c|c|c|}
\hline Variables & Frequency & $\%$ & $95 \% \mathrm{Cl}$ \\
\hline \multicolumn{4}{|l|}{ Adherence status } \\
\hline Complete adherence & 166 & 86.0 & $(80.1-90.4)$ \\
\hline Nonadherence & 27 & 14.0 & $(9.6-19.9)$ \\
\hline \multicolumn{4}{|c|}{ Adherence status by type of ACT } \\
\hline \multicolumn{4}{|l|}{ Artemether-lumefantrine } \\
\hline Complete adherence & 152 & 85.4 & $(79.1-90.1)$ \\
\hline Nonadherence & 26 & 14.6 & $(9.9-20.9)$ \\
\hline \multicolumn{4}{|l|}{ Artesunate-amodiaquine } \\
\hline Complete adherence & 14 & 93.3 & $(66.0-99.7)$ \\
\hline Nonadherence & 1 & 6.7 & $(0.3-34.0)$ \\
\hline
\end{tabular}

Abbreviation: ACT, artemisinin-based combination therapy.

\section{ACTs dispensed and adherence level to ACTs in Nanoro health district}

Table 3 summarizes the study participant's adherence to ACT. All patients received the correct ACT regimen prescription from $\mathrm{HCW}$ according to the patient age group (details about dosing schedule for ACT are given in Tables $\mathrm{S} 1$ and S2), in terms of duration of treatment and recommended number of tablets. Regarding the type of antimalarial drug delivered to the patient, $92.5 \%(184 / 199)$ were prescribed oral AL and 7.5\% ASAQ. Of the 193 patients available at day $5 \pm 2$ home visit, $166(86.0 \%)$ were classified as "complete adherence", whereas 27 (14.0\%) were classified as "nonadherent". Considering the adherence level according to the type of ACT prescribed, we noticed that $85.4 \%$ and $93.3 \%$ were completely adherent to AL and ASAQ, respectively.

\section{Factors explaining nonadherence to} ACTs in Nanoro health district

From the results presented in Table 4, the nonadherence of the patients was significantly and negatively associated with uneasy affordability of ACT (OR: 0.26; 95\% CI: 0.07-0.70). However, nonadherence to ACT was higher among the participants who did not receive any advice from HCWs

Table 4 Proportion of nonadherence and factors explaining nonadherence to the ACTs

\begin{tabular}{|c|c|c|c|c|c|}
\hline & \multirow{2}{*}{$\begin{array}{l}\text { Nonadherence } \\
\mathrm{N}=\mathbf{2 7}\end{array}$} & \multicolumn{2}{|l|}{ Univariate } & \multicolumn{2}{|l|}{ Multivariable } \\
\hline & & OR (95\% CI) & $P$-value & Adj OR (95\% CI) & \\
\hline \multicolumn{6}{|l|}{ Gender $^{\mathrm{a}}$} \\
\hline Female & $10(9.8)$ & I & & & \\
\hline Male & $17(18.9)$ & $2.12(0.92-5.12)$ & 0.07 & & \\
\hline \multicolumn{6}{|l|}{$\mathrm{Age}^{\mathrm{a}}$} \\
\hline 5 years and above & $7(14.6)$ & I & & & \\
\hline Under 5 years & $20(13.9)$ & $0.93(0.38-2.56)$ & 0.90 & & \\
\hline \multicolumn{6}{|c|}{ Easy affordability of $\mathrm{ACT}^{\mathrm{a}}$} \\
\hline Yes & $23(19.0)$ & $\mathrm{I}$ & & & \\
\hline No & $4(5.6)$ & $0.26(0.07-0.70)$ & 0.010 & & \\
\hline \multicolumn{6}{|l|}{ Blood sample taken ${ }^{a}$} \\
\hline Yes & $19(11.8)$ & 1 & & 1 & \\
\hline No & $8(25.8)$ & $2.60(0.98-6.56)$ & 0.050 & $1.49(0.55-4.03)$ & 0.14 \\
\hline \multicolumn{6}{|c|}{ Received advices from $\mathrm{HCW}^{\mathrm{a}}$} \\
\hline Yes & $6(7.8)$ & I & & I & \\
\hline No & $21(18.3)$ & $2.59(1.04-7.47)$ & 0.041 & $3.21(1.13-9.12)$ & 0.019 \\
\hline \multicolumn{6}{|c|}{ First dose of $\mathrm{ACT}$ taken at $\mathrm{HF}^{\mathrm{a}}$} \\
\hline Yes & $13(10.8)$ & $\mathrm{I}$ & & & \\
\hline No & $14(19.4)$ & $1.98(0.86-4.57)$ & 0.10 & & \\
\hline $\begin{array}{l}\text { Number of ACT } \\
\text { tablets }^{\mathrm{b}}\end{array}$ & $6.0(3.0-24.0)$ & $\mathrm{I} .04(0.97-\mathrm{I} . \mathrm{II})$ & 0.19 & & \\
\hline Number of $\mathrm{CM}^{\mathrm{b}}$ & $2.0(0.0-4.0)$ & $1.03(0.61-1.72)$ & 0.92 & & \\
\hline \multicolumn{6}{|l|}{ Fever after treatment ${ }^{\mathrm{a}}$} \\
\hline No & $24(13.8)$ & 1 & & & \\
\hline Yes & $3(16.7)$ & $1.29(0.27-4.36)$ & 0.72 & & \\
\hline \multicolumn{6}{|l|}{ Side effects of $A C T^{a}$} \\
\hline No & $9(10.3)$ & 1 & & & \\
\hline Yes & $18(17.1)$ & $1.77(0.76-4.40)$ & 0.18 & & \\
\hline
\end{tabular}

Notes: ${ }^{a}$ Represents data presented in number (\%); ${ }^{b}$ represents data presented in median (minimum-maximum). Statistically significant values are shown in bold $(P<0.05)$. Abbreviations: Adj, adjusted; ACT, artemisinin-based combination therapy; CM, concomitant medication; HCW, health care worker; HF, health facility. 
(OR: 2.64; 95\% CI: 1.07-7.51). Additionally, this simple logistic regression tended to confirm that the nonadherence to ACTs was higher among participants who did not have blood sample collection for malaria confirmation, but this association was not statistically significant.

The age of the participant and gender, the directly observed treatment strategy, and the occurrence of adverse events were not significantly associated with the proportion of nonadherence. In multivariable analysis only, patients or caregivers who did not receive advices from HCWs exhibited an association with nonadherence (adjusted OR: 3.21; 95\% CI: 1.13-9.12).

No association analysis stratified by age group (under 5 vs 5 years and above) was performed because the number of participants up to the age of 5 years was too small.

\section{Discussion}

Eleven years after the introduction of ACTs into the national policy for the uncomplicated malaria treatment, it was crucial to have an overview of their real-life outcomes in terms of adherence in the mindset of improving the effectiveness of this valuable drug in hyperendemic malaria area. Our study was designed to assess adherence level and factors that influence adherence level in rural area of Burkina Faso where the population is more vulnerable and where the prevalence of poverty was estimated at $47.5 \%$ in rural areas in $2014 .{ }^{37}$ Malaria is an acute infectious disease caused by the parasite Plasmodium falciparum in most cases, and when the episode is mismanaged (inappropriate use of ACTs), it can result into severe forms often leading to patient death and/or emergence of resistance to plasmodium. ${ }^{18,27}$

The ultimate goal of malaria treatment by using ACTs was to have an adherence level close to $100 \%$. Considering this reference, the findings of this study revealed that the adherence level (86.0\%) was not optimum. However, this adherence proportion is consistent with the findings of other studies in Tanzania, Madagascar, Ghana, Nigeria, Uganda, and Iran, where similar adherence levels to ACTs were reported. ${ }^{38-41}$ Nevertheless, adherence level found in our study area was higher than that obtained from other studies conducted in Ghana, Kenya, Malawi, and Sierra Leone, where adherence level was estimated at 57.3, 42.1, 64.1, and 57.0, respectively. ${ }^{21-24,38}$ This "relative high level of adherence" to ACTs in our study could be explained partly by the improvement in information, education, and communication (IEC) strategies and materials associated with the implementation of regular sensitizing campaigns focusing on malaria. These strategies include home visits, community theaters, focus group discussions, and school-based information campaigns.
In 2016, the number of IEC sessions conducted on the topic of malaria in the study area was estimated at 691 sessions and involved 8,743 people, and this approach had resulted in an increase of awareness among the population that malaria is a serious illness that can lead to death if the treatment regimen is not respected. ${ }^{15,16}$ In addition, health professionals are continually being trained and are likely to pay more attention to the information given to patients. Furthermore, this "relative high level of adherence" can be also attributed to the impact of clinical research activities on the local community. Indeed, after the creation of Clinical Research Unit of Nanoro in 2009 , the community is continually sensitized through research clinicians/nurses and field workers in the framework of clinical trial activities (during patients' screening, enrollment, and follow-up visits) on the good practice of malaria treatment and prevention. ${ }^{31,42,43}$

In our study area, despite the low cost of ASAQ $(0.46 €)$ compared to $\mathrm{AL}(1.52 €)$, the latter was the most frequent ACT dispensed by the HCW. This could be explained by the poor safety profile of ASAQ, since it is associated with adverse events such as asthenia, blurred vision, general weakness, vomiting, and dizziness, which are commonly reported in the literature and can be attributed to the amodiaquine component of the drug. ${ }^{44-47}$ In addition, since 2016, with the implementation of seasonal malaria chemoprophylaxis (SMC) in children aged 3-59 months, who represent the three-quarters of our study population, treatment of malaria in this age group should not include either amodiaquine or combination drugs containing amodiaquine, such as ASAQ. ${ }^{48}$ However, the only alternative free of charge/subsidized ACT available in the public sector which does not contain amodiaquine is AL. It is true that the period of our study (May 2017 to August 2017) did not totally overlap with the SMC period (August to November), but it could be possible that the HCWs have developed the attitude/reflex to no longer prescribe ASAQ even outside the SMC period.

Our findings also show that patients who did not receive advice from HCW are positively associated with nonadherence to ACTs in the univariate and multivariable analyses. This means that patients still seek care or complete treatment from other sources such as traditional/herbal drugs, or did not eliminate all parasites completely from the bloodstream, which is again a source of treatment failure. This could be partly explained by the influence of cultural practices. According to $\mathrm{WHO}$, up to $80 \%$ of the population living in developing countries relies on traditional or herbal medicines for their primary care needs. ${ }^{49}$ These practices could lead to several adverse drug reactions and most likely increase the risk of selection and spread of drug resistance. ${ }^{17,49}$ This highlights the 
fact that improving HCW practices and counseling of patients during medical care is likely to increase patient knowledge and improve adherence level. Likewise, improvement in the daily attitude of HCWs and practices could strengthen the confidence of communities using health facility services.

In our study, patients for whom blood collection (RDT) was not performed before treatment prescription seemed to be less adherent (in the univariate analysis, with a trend when considering multivariable analysis). As a patient, the benefit of pathology confirmation by biology (pathogen identification) increases the patient confidence about the diagnosis of his/her disease, providing him a better sense of treatment and therefore ownership over the adherence. This is in agreement with the fact that adherence has been qualified as "the key mediator between medical practice and patient outcomes". ${ }^{50}$ This finding highlights the importance of Test-Treat-Track initiative recommend by WHO to provide a framework for endemic countries to control and eliminate malaria completely. ${ }^{6}$

This study also showed a significant association between patients who cannot easily afford their medicine (ACTs) and adherence level. However, this latter variable was not retained as an explanatory factor for multivariable analysis.

One of the strengths of our study was the study design. The study staff interviewed participants during their exit visit and the day following the last treatment, which allowed to minimize the memory bias. However, on the other hand, this strength could be also seen as a limitation. Indeed, the accuracy of adherence level measurement is partially linked also to the study design. Because the participants were aware of future follow-ups in the form of home visits (day $5 \pm 2$ ) after drug prescription, the adherence level may be influenced positively. Another limitation of the study is the fact that the great majority of patients included were children under 5 years of age. So, the sample might not be representative of the national population, and therefore it may be difficult to extrapolate these results to the general population. However, it is interesting to note that these findings gave a crucial overview on the adherence level among the most vulnerable population in SSA. Indeed, children under 5 years of age are the most vulnerable group affected by malaria. In 2017 , they accounted for $61 \%(266,000)$ of all malarial deaths worldwide. ${ }^{2}$ Our findings should be interpreted keeping these strengths and limitations in mind.

\section{Conclusion}

In Nanoro rural settings, adherence to ACTs was interestingly high, especially among those who received advices from HCWs. Though these observations are encouraging, efforts still need to be deployed to increase awareness among the population in order to ensure sustainability. This might contribute to a delay in the emergence of drug resistance to ACTs. The Test-Treat-Track policy together with increasing awareness in patients regarding malaria and the prescribed treatment may improve adherence and should be highly promoted. Additionally, to address patient nonadherence to medication, strategies to strengthen communication between HCWs and the patient should be given greater consideration.

\section{Acknowledgments}

We are very grateful to all participants who participated in the study. We would like to thank everyone who supported this study directly or indirectly through fieldwork, data collection, or analysis support. The research team would like to thank its partners: National Malaria Control Program in Burkina Faso, INDEPTH Network, and Shinpoong Group, South Korea. The field work of this study was sponsored by the INDEPTH Network, thanks to a grant offered by the Bill \& Melinda Gates Foundation.

\section{Disclosure}

The authors report no conflicts of interest in this work.

\section{References}

1. World Health Organization. Malaria control improves for vulnerable in Africa, but global progress off-track. Geneva: WHO; 2016. Available from: http://www.who.int/mediacentre/news/releases/2016/malariacontrol-africa/en/. Accessed September 28, 2017.

2. World Health Organization. World Malaria Report 2018. Geneva: WHO; 2018. Available from: http://apps.who.int/iris/bitstr eam/10665/162441/1/9789241549127_eng.pdf. Accessed September 16,2018 .

3. World Health Organization. Guidelines for The Treatment of Malaria. Geneva: WHO; 2015.

4. Lindblade KA, O’Neill DB, Mathanga DP, Katungu J, Wilson ML. Treatment for clinical malaria is sought promptly during an epidemic in a highland region of Uganda. Trop Med Int Health. 2000;5(12):865-875.

5. Baird JK. Effectiveness of antimalarial drugs. $N$ Engl J Med. 2005; 352(15):1565-1577.

6. World Health Organization [homepage on the Internet]. T3: Test. Treat. Track initiative. Geneva: WHO; 2016. Available from: https://www. who.int/malaria/areas/test_treat_track/en/. Accessed December 2, 2018.

7. Guiguemdé TR, Gbary AR, Ouedraogo JB, et al. [Current aspects of malarial chemoresistance of subjects autochthonous in the OCCGE countries (West Africa)]. Ann Soc Belg Med Trop. 1991;71(3): 199-207. French.

8. Guiguemde TR, Aouba A, Ouedraogo JB, Lamizana L. Ten-year surveillance of drug-resistant malaria in Burkina Faso (1982-1991). Am J Trop Med Hyg. 1994;50(6):699-704.

9. Ministry of Health/National Malaria Control Program. [National Guidelines for the Diagnosis, Treatment, and Prevention of Malaria in Burkina Faso] Directives Nationales pour La prise en charge Du paludisme Au Burkina Faso. Burkina Faso; 2017. French.

10. National Institute of Statistic and Demography and ICF International. [Demographic and Health and Multiple Indicator Cluster Survey (DHSBF-MICSIV)] Enquête Démographique et de Santé et Indicateurs Multiples (EDSBF-MICS IV) 2010. Calverton, Maryland; 2012. French. 
11. Koulidiati JL, De Allegri M, Souares A, et al. Factors associated with effective coverage of child health services in Burkina Faso. Trop Med Int Health. 2018;23(11):1188-1199.

12. SIG: Service d'Information du Gouvernement - Burkina Faso. Compte rendu du Conseil des ministres du mercredi 02 mars 2016. Available from: http://www.sig.bf/2016/03/compte-rendu-du-conseil-desministres-du-mercredi-02-mars-2016/. Accessed November 24, 2018.

13. Ridde V, Nitièma AP, Dadjoari M. [Improve the accessibility of essential drugs for the populations of one medical region in Burkina Faso] Sante. 2005;15(3):175-182. French.

14. Ministry of Health/Directorate General of Studies and Sectoral Statistics. Statistical Yearbook 2017. Burkina Faso; 2018.

15. Ministry of Health/Directorate General of Studies and Sectoral Statistics. Statistical Yearbook 2016. Burkina Faso; 2017. French.

16. National Malaria Control Program and US President's Malaria Initiative. Malaria Operational Plan Fiscal Year (FY) 2017. NMCP and U.S. Global Malaria Coordinator. Burkina Faso; 2016.

17. White NJ, Pongtavornpinyo W, Maude RJ, et al. Hyperparasitaemia and low dosing are an important source of anti-malarial drug resistance. Malar J. 2009;8(1):253.

18. World Health Organization. Global report on antimalarial efficacy and drug resistance: 2000-2010. Geneva: WHO, 2017. Available from: https://www.who.int/malaria/publications/atoz/9789241500470/en/. Accessed August 22, 2018.

19. Nzila A, Okombo J, Ohuma E, Al-Thukair A. Update on the in vivo tolerance and in vitro reduced susceptibility to the antimalarial lumefantrine. J Antimicrob Chemother. 2012;67(10):2309-2315.

20. Adjuik M, Babiker A, Garner P, et al. Artesunate combinations for treatment of malaria: meta-analysis. Lancet. 2004;363(9402):9-17.

21. Amponsah AO. Patient related factors affecting adherence to antimalarial medication in an urban estate in Ghana. Malar Res Treat. 2015; 2015:452539.

22. Lawford H, Zurovac D, O'Reilly L, et al. Adherence to prescribed artemisinin-based combination therapy in Garissa and Bunyala districts, Kenya. Malar J. 2011;10(1):281.

23. Onyango EO, Ayodo G, Watsierah CA, et al. Factors associated with non-adherence to artemisinin-based combination therapy (ACT) to malaria in a rural population from holoendemic region of Western Kenya. BMC Infect Dis. 2012;12(1):143.

24. Mace KE, Mwandama D, Jafali J, et al. Adherence to treatment with artemether-lumefantrine for uncomplicated malaria in rural Malawi. Clin Infect Dis. 2011;53(8):772-779.

25. Cohen JL, Yavuz E, Morris A, Arkedis J, Sabot O. Do patients adhere to over-the-counter artemisinin combination therapy for malaria? Evidence from an intervention study in Uganda. Malar J. 2012;11(1):83.

26. Barnes KI, Durrheim DN, Little F, et al. Effect of artemetherlumefantrine policy and improved vector control on malaria burden in KwaZulu-Natal, South Africa. PLoS Med. 2005;2(11):e330.

27. Dondorp AM, Nosten F, Yi P, et al. Artemisinin resistance in Plasmodium falciparum malaria. $N$ Engl J Med. 2009;361(5):455-467.

28. Ashley EA, Dhorda M, Fairhurst RM, et al. Spread of artemisinin resistance in Plasmodium falciparum malaria. N Engl J Med. 2014;371(5): 411-423.

29. Lu F, Culleton R, Zhang M, et al. Emergence of indigenous artemisinin-resistant Plasmodium falciparum in Africa. $N$ Engl J Med. 2017;376(10):991-993.

30. Banek K, Lalani M, Staedke SG, Chandramohan D. Adherence to artemisinin-based combination therapy for the treatment of malaria: a systematic review of the evidence. Malar J. 2014;13(1):7.

31. Derra K, Rouamba E, Kazienga A, et al. Profile: Nanoro health and demographic surveillance system. Int J Epidemiol. 2012;41(5):1293-1301.

32. World Health Organization. The World Health Report 2006-Chapter 1. Health workers: a global profile. Geneva: WHO; 2006. Available from: http://www.who.int/whr/2006/06_chap1_en.pdf. Accessed December $02,2018$.
33. Brown MT, Bussell JK. Medication adherence: who cares? Mayo Clin Proc. 2011;86(4):304-314.

34. Farmer KC. Methods for measuring and monitoring medication regimen adherence in clinical trials and clinical practice. Clin Ther. 1999;21(6): 1074-1090.

35. Brunette W, Sundt M, Dell N, et al. Open data kit 2.0: Expanding and refining information services for developing regions. In Proceedings of the 14th Workshop on Mobile Computing Systems and Applications; February 26-27, 2013; Jekyll Island, GA. Article 10.

36. Raja A, Tridane A, Gaffar A, Lindquist T, Pribadi K. Android and ODK based data collection framework to aid in epidemiological analysis. Online J Public Health Inform. 2014;5(3):228.

37. Institut national de la statistique \& et de la démographie (INSD). Rapport Enquête multisectorielle continue (EMC) 2014 Profil de pauvreté et d'inégalités. 2015.

38. Ajayi IO, Browne EN, Garshong B, et al. Feasibility and acceptability of artemisinin-based combination therapy for the home management of malaria in four African sites. Malar J. 2008;7(1):6.

39. Ratsimbasoa A, Ravony H, Vonimpaisomihanta JA, et al. Compliance, safety, and effectiveness of fixed-dose artesunate-amodiaquine for presumptive treatment of non-severe malaria in the context of home management of malaria in Madagascar. Am J Trop Med Hyg. 2012; 86(2):203-210.

40. Simba DO, Kakoko D, Tomson G, et al. Adherence to artemether/ lumefantrine treatment in children under real-life situations in rural Tanzania. Trans R Soc Trop Med Hyg. 2012;106(1):3-9.

41. Ogolla JO, Ayaya SO, Otieno CA. Levels of adherence to coartem $C$ in the routine treatment of uncomplicated malaria in children aged below five years, in Kenya. Iran J Public Health. 2013;42(2):129-133.

42. Fitchett JR. Ethical considerations of clinical trials in the developing world. Trans R Soc Trop Med Hyg. 2009;103(8):756-760.

43. Tinto H, Valea I, Sorgho H, et al. The impact of clinical research activities on communities in rural Africa: the development of the clinical research unit of Nanoro (CRUN) in Burkina Faso. Malar J. 2014; 13(1):113

44. PREGACT Study Group, Pekyi D, Ampromfi AA, et al. Four artemisinin-based treatments in African pregnant women with malaria. $N$ Engl J Med. 2016;374(10):913-927.

45. Sirima SB, Tiono AB, Gansané A, et al. The efficacy and safety of a new Fixed-dose combination of amodiaquine and artesunate in young African children with acute uncomplicated Plasmodium falciparum. Malar J. 2009;8(1):48.

46. Tagbor H, Bruce J, Browne E, Randal A, Greenwood B, Chandramohan D. Efficacy, safety, and tolerability of amodiaquine plus sulphadoxinepyrimethamine used alone or in combination for malaria treatment in pregnancy: a randomised trial. Lancet. 2006;368(9544):1349-1356.

47. Schramm B, Valeh P, Baudin E, et al. Tolerability and safety of artesunate-amodiaquine and artemether-lumefantrine fixed dose combinations for the treatment of uncomplicated Plasmodium falciparum malaria: two open-label, randomized trials in Nimba County, Liberia. Malar J. 2013;12(1):250.

48. World Health Organization. WHO Policy Recommendation: Seasonal Malaria Chemoprevention (SMC) for Plasmodium falciparum Malaria control in Highly Seasonal Transmission Areas of the Sahel Sub-region in Africa. Geneva: WHO; 2015. Available from: http://www.who. int/malaria/publications/atoz/who_smc_policy_recommendation/en/. Accessed May 23, 2018.

49. World Health Organization [homepage on the Internet]. New WHO guidelines to promote proper use of alternative medicines. Geneva: WHO; 2010. Available from: http://www.who.int/mediacentre/news/ releases/2004/pr44/en/. Accessed December 3, 2018.

50. Kravitz RL, Melnikow J. Medical adherence research: time for a change in direction? Med Care. 2004;42(3):197-199. 


\section{Supplementary materials}

Table SI Dosing schedule for artesunate-amodiaquine

\begin{tabular}{|l|l|l|l|l|}
\hline Weight (age) & Presentation and dosage & Day 0 & Day I & Day 2 \\
\hline$>4.5-<9 \mathrm{~kg}(2-1 \mathrm{I}$ months) & $\begin{array}{l}\text { Artesunate } 25 \mathrm{mg} \\
\text { Amodiaquine } 67.5 \mathrm{mg}\end{array}$ & I tablet & I tablet & I tablet \\
\hline$>9-<18 \mathrm{~kg}$ (I-5 years) & $\begin{array}{l}\text { Artesunate } 25 \mathrm{mg} \\
\text { Amodiaquine } 67.5 \mathrm{mg}\end{array}$ & I tablet & I tablet & I tablet \\
\hline$>18-<36 \mathrm{~kg}$ (6-13 years) & $\begin{array}{l}\text { Artesunate } 25 \mathrm{mg} \\
\text { Amodiaquine } 67.5 \mathrm{mg}\end{array}$ & I tablet & I tablet & I tablet \\
\hline$>36 \mathrm{~kg}(>14$ years) & $\begin{array}{l}\text { Artesunate } 25 \mathrm{mg} \\
\text { Amodiaquine } 67.5 \mathrm{mg}\end{array}$ & 2 tablets & 2 tablets & 2 tablets \\
\hline
\end{tabular}

Note: Based on the National Guidelines for the Diagnosis, Treatment, and Prevention of Malaria in Burkina Faso.'

Table S2 Dosing schedule for artemether-lumefantrine

\begin{tabular}{|l|l|l|l|l|}
\hline Weight (age) & Presentation and dosage & Day $\mathbf{0}$ & Day I & Day $\mathbf{2}$ \\
\hline $5-14 \mathrm{~kg}(<3$ years $)$ & $\begin{array}{l}\text { Artemether } 20 \mathrm{mg} \\
\text { Lumefantrine } 120 \mathrm{mg}\end{array}$ & $\mathrm{I}$ tablet $\times 2$ & $\mathbf{I}$ tablet $\times 2$ & $\mathbf{I}$ tablet $\times 2$ \\
\hline $15-24 \mathrm{~kg}(\geq 3-8$ years) & $\begin{array}{l}\text { Artemether } 20 \mathrm{mg} \\
\text { Lumefantrine } 120 \mathrm{mg}\end{array}$ & 2 tablets $\times 2$ & 2 tablets $\times 2$ & 2 tablets $\times 2$ \\
\hline $25-34 \mathrm{~kg}(\geq 9-14$ years) & $\begin{array}{l}\text { Artemether } 20 \mathrm{mg} \\
\text { Lumefantrine } 120 \mathrm{mg}\end{array}$ & 3 tablets $\times 2$ & 3 tablets $\times 2$ & 3 tablets $\times 2$ \\
\hline$>34 \mathrm{~kg}(>14$ years $)$ & $\begin{array}{l}\text { Artemether } 20 \mathrm{mg} \\
\text { Lumefantrine } 120 \mathrm{mg}\end{array}$ & 4 tablets $\times 2$ & 4 tablets $\times 2$ & 4 tablets $\times 2$ \\
\hline
\end{tabular}

Note: Based on the National Guidelines for the Diagnosis, Treatment, and Prevention of Malaria in Burkina Faso.'

\section{Reference}

1. Ministry of Health/National Malaria Control Program. [National Guidelines for the Diagnosis, Treatment, and Prevention of Malaria in Burkina Faso] Directives Nationales pour La prise en charge Du paludisme Au Burkina Faso. Burkina Faso; 2017. French.

\section{Publish your work in this journal}

Patient Preference and Adherence is an international, peer-reviewed, open access journal that focuses on the growing importance of patient preference and adherence throughout the therapeutic continuum. Patient satisfaction, acceptability, quality of life, compliance, persistence and their role in developing new therapeutic modalities and compounds to optimize clinical outcomes for existing disease states are major areas of interest for the journal. This journal has been accepted for indexing on PubMed Central. The manuscript management system is completely online and includes a very quick and fair peer-review system, which is all easy to use. Visit http://www. dovepress.com/testimonials.php to read real quotes from published authors. 